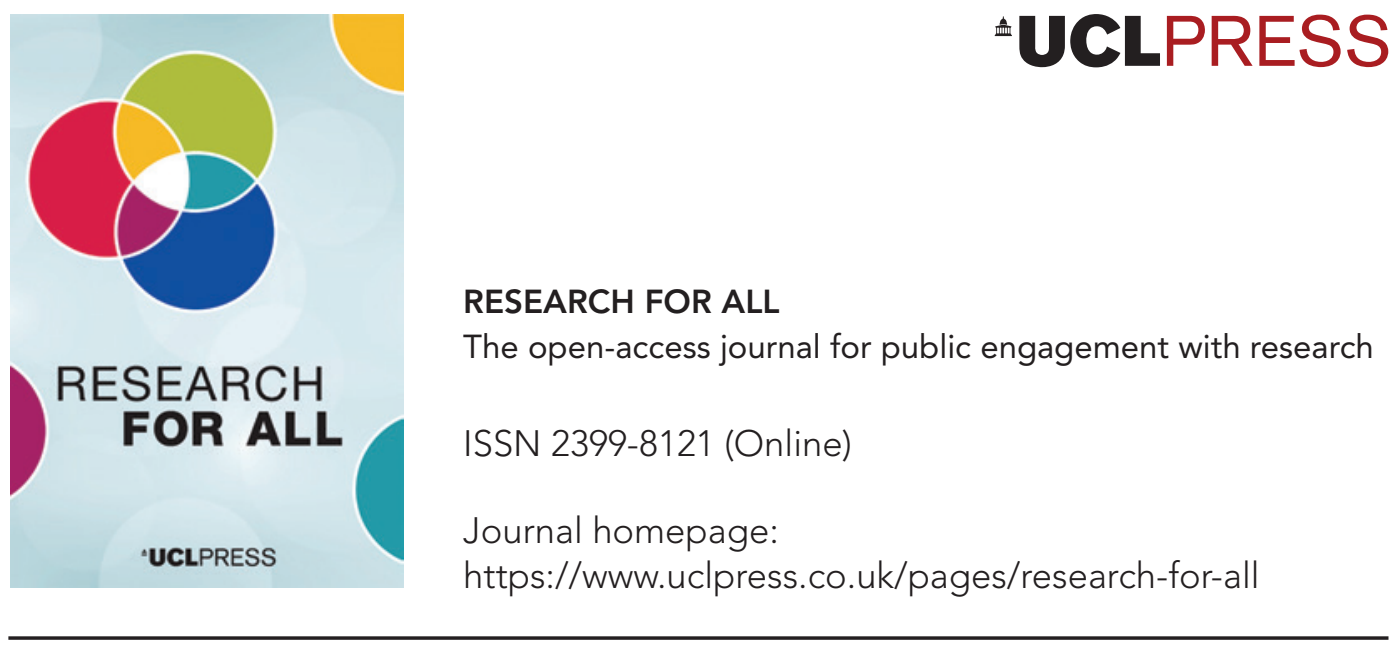

\title{
Editorial: Engagement for change
}

\section{Sophie Duncan (iD and Sandy Oliver (iD}

\section{How to cite this article}

Duncan, S. and Oliver, S. (2021) 'Editorial: Engagement for change'. Research for All, 5 (2), 188-93. https://doi.org/10.14324/RFA.05.2.01

Publication date: 21 September 2021

\section{Copyright}

(C) 2021 Duncan and Oliver. This is an open-access article distributed under the terms of the Creative Commons Attribution Licence (CC BY) 4.0 https://creativecommons.org/licenses/ by/4.0/, which permits unrestricted use, distribution and reproduction in any medium, provided the original authors and source are credited.

\section{Open access}

Research for All is a peer-reviewed open-access journal. 


\title{
Editorial: Engagement for change
}

\author{
Sophie Duncan* - National Co-ordinating Centre for Public Engagement, UK \\ Sandy Oliver* - UCL Institute of Education, UK
}

A scan of previous issues of Research for All bears testimony to the breadth and depth of practices that seek to engage the public with research. This diversity of practices is to be welcomed. It recognizes that engagement has many different faces, and different outcomes, and that collectively opening up research to the public has value to society and to research.

We therefore welcome contributions about all forms of engagement with research, whatever the languages used to describe it. Covering outreach, science communication, community engagement, patient involvement, public engagement and knowledge exchange, the journal's pages have captured the learning from the breadth of approaches undertaken across the world.

In our opening issue, we reflected on this broad territory of public engagement by using the metaphor of a map (Duncan and Oliver, 2017a): many of us occupy just one part of the territory, where we are very comfortable; other areas are much less familiar, but offer the opportunity of new vistas. We sought to create a space in the journal to reflect on different practices, and to share actionable learning.

What all these practices share is a commitment to mutual benefit (NCCPE, n.d.). Wherever public engagement happens, there should be benefits for all involved. In the UK, inspired by the Economic and Social Research Council's impact toolkit, and informed by an analysis of impact case studies from the UK Research Excellence Framework (NCCPE, 2016), the National Co-ordinating Centre for Public Engagement describes three main impacts from public engagement (NCCPE, 2018):

- Conceptual impacts: improving knowledge and understanding, encouraging empathy, and changing how people think

- Capacity building (or capability): changing what people do, by improving networks, capabilities and skills

- Innovation: changing how the world works, by informing policy, changing systems and addressing social inequalities.

As suggested by the definition of public engagement, these outcomes are relevant to all involved: the researchers, publics and collaborators.

At the time of writing, we are four years on from the launch of the journal, and in the midst of a global pandemic. It is therefore helpful to pause and reflect on what we are learning together about the practices of engagement that lead to these important impacts. In our editorials, we have reflected through the Johari window, to consider our positionality when it comes to working together (Oliver and Duncan, 2019), and we have recognized the deeply human elements involved in effective engagement (Duncan and Oliver, 2019), and the time it takes to cultivate effective collaborations and practices (Oliver and Duncan, 2020). We have considered what makes learning new or innovative (Oliver and Duncan, 2021), and how the global COVID-19 pandemic is both impacting engaged ways of working, and illustrating how they have value (Duncan and Oliver, 2020). 
And we have considered the motivations for engagement (Duncan and Oliver, 2017b) and creating conditions where effective practices can thrive (Duncan and Oliver, 2018).

This current issue opens up reflections on a range of different engagement practices and impacts, and invites a conversation on the processes needed to create fertile ground for making a difference to research, researchers and society. Many of the papers reflect on the practice of knowledge exchange. Another common term to describe the processes of engagement with research, knowledge exchange has become a clear policy agenda in the UK over the last ten years. As a consequence, there has been significant investment in enabling and supporting effective knowledge exchange between different groups of people. Knowledge exchange seeks to ensure that everyone involved changes as a result of this exchange, and therefore that collaborations grow and develop over time.

We are therefore delighted to showcase a special collection of papers, drawn from a 2019/20 seminar series on Knowledge Exchange and the Creative Industries. Cole's paper introduces the collection, comprising her piece along with Clarke, Dawson et al., Gray et al. and Moreton, and all these papers are introduced more fully in the account below. Considering the practices reflected on in the seminar series, Cole notes that academia and the creative industries are primarily vocational sectors and, as a consequence, can lead people to dive into collaborative working without putting the necessary procedures in place to protect all those involved. This tension between having the time to develop a relationship, and the need for more formal processes surrounding ethics and intellectual property, sits at the heart of these types of activities, and there are no easy solutions to address it.

Several papers reflect specifically on conceptual impacts, and on the role of oneoff interventions, which are an important part of the engagement landscape. Sadler's longitudinal study on the long-term impact of science shows (one-off, interactive events for families) suggests that two and a half years after the event, the shows continue to be remembered, and, in some cases, the learning has been applied. Mathieson and Duca share their approach to STEM (science, technology, engineering and mathematics) engagement using the entertaining format of an escape room, unusually within the context of a science centre. They demonstrate how the format encouraged participants to engage with complex scientific ideas. And Keith and Griffiths share an approach to enabling young people living in a deprived area of the UK to engage with science. Their novel methodology, SCENE (STEAM, community, enquiry, narrative, entertainment), has evolved over the five years that their festival has been running, and they have used evaluation as a critical friend, to develop, change and grow, to meet the interests and needs of their target participants.

Conceptual impacts are often a necessary part of achieving capacity-building impacts. It is hard to change how people work, without first improving knowledge and understanding. For example, Dawson et al. explore the creative and lived experience of grief, through creating a fiction film, providing a rich sensory and emotional engagement experience. They reflect on how this changed the thinking and practice of the co-researchers, but caution that while the experience of a fiction film can be therapeutic, for some it can be really unhelpful. Film-making is also picked up in a paper by Pick et al., who were keen to develop a collaborative approach to working with young people to explore brainwashing in the Cold War. Using visual essay films created a space for the young people to reflect on the social influences that affected them, and informed the thinking of the researchers involved.

Capacity-building impacts are also explored in three further papers. Bridges sought to address lack of engagement with classics through a targeted funding call, 
offering small amounts of funding to enable researchers to develop engagement plans. She shares how to use this as a culture change resource, through offering feedback on unsuccessful projects, and providing a platform to share outputs. Salter et al. reflect on the relationship between engagement, impact and participation at a baby and child lab, where sharing the latest research in developmental psychology with new parents built trust and understanding, with the consequence that many went on to be participants in research. And Sheppard et al. consider the value of patient and public involvement for a county hospital, and remind us of how valuable this can be for researchers and publics, the investment of time needed to develop effective mutually beneficial ways of working, and the need for key people to act as facilitators and brokers of engagement.

The third impact area, innovation, is explored by Moreton, who hopes to see innovation in policymaking. His paper shares insights from a long-term programme, Research and Enterprise in Arts and Creative Technology (REACT), which brought creative practitioners and researchers into dialogue together, and provides a useful framing of the role of creativity within modern economies, before exploring the challenge of the instrumental measures used to assess the value of knowledge exchange collaborations. The paper reflects on the need to walk a line, balancing complicity and resistance to the politics in order to be effective. He cautions that 'we must remain vigilant to how we are reinforcing problematic concepts of market-driven creativity through our work, even when we are trying our hardest to reimagine those concepts as something brighter or more progressive' (286).

Innovation impacts are also needed when considering support mechanisms to enable effective practice. These include audience insight and understanding, to help shape the approach, as explored by Dreyer et al., whose European project sought to inform the design of public dialogue through exploring the views of potential dialogue participants. They found that those interested in getting involved wanted to see the relevance to them, to be actively involved in the dialogue, and to understand the resource implications of taking part at the start.

Innovation impacts are also illustrated by Stelfox et al. and Clarke. Stelfox et al. developed a collaborative knowledge exchange approach around research, in order to improve lives of turtles and people. Their paper describes how collectively they are addressing the issues raised by turtles becoming entangled in fishing tackle, and demonstrate how this has refocused the research questions, and supported the development of education programmes for local people and tourists, and a turtle rescue centre in the Maldives. Clarke describes a digital placemaking toolkit that inspires people to reimagine new futures for their places. The toolkit itself seeks to change how publics are involved in planning processes. Co-production sits at the heart of the development, ensuring that all those involved undergo change. He explores the need for consequence scanning, to look at positive and negative outcomes that could arise from the collaboration, and to agree how these would be handled.

The impacts illustrated across these papers help us realize the mutually beneficial effects of engagement. However, our papers also touch on some of the unintended impacts, or the challenges of working in these ways. Our authors remind us of the costs of long-term collaborative approaches to working together, and provide useful insights as to how to ensure that these working relationships can work well.

For example, Gray et al.'s honest reflections on the costs of researchers and dramatists coming together, and the assumptions made about how the partnership could work, remind us that priorities may be different depending on your context. The collaboration sought to engage school students with virtual reality, and the authors reflect on the tensions that arose from these different priorities, with a theatre company 
who were keen to enable more emergent practices, and a team of researchers who needed to get the appropriate ethical sign-off, and therefore needed to plan every aspect of the work.

The recognition that knowledge exchange requires significant understanding, skills and competencies is emphasized by Morris and Stevenson in their paper looking at the dynamics of working at the intersections, in this case between academics and policymakers. They explore the hidden dynamics of knowledge exchange, most particularly the effect of inequities between the collaborators.

To cultivate high-quality, impactful engagement is difficult, and takes a lot of time. In their paper, Ní Shúilleabháin et al. consider an approach to integrating public engagement into the culture of a research institution. Building a community of practice created an effective mechanism to share learning, and to celebrate excellence. They reflect on the time taken to build shared understanding of engagement, and the need for senior leaders to support the work and give lots of practical ideas for embedding engagement.

This issue is rich, reflecting the complexity of engagement with research, and the breadth and depth of learning available from those who have been working at the intersection of research and society.

As the journal has developed and grown, we reflect the maturing of a sector, deeply committed to engaged ways of working, and keen to build an evidence base that is informed by all those involved in engagement with research. The journal is creating a space for exploring what the broad discipline of public engagement with research might look like, and cultivating shared learning. As a consequence, Research for All is evolving too. We are moving to a journal where articles are published when they are ready, rather than in two issues per year, enabling us to save time for authors who are keen to make their work available, and for readers to get access as soon as possible. We are providing more guidance for authors; inviting potential contributors to share their learning points before sharing their papers, to help identify where the value of the work lies from the point of view of our readers; and encouraging papers that span the breadth of all forms of research engagement, from across the world.

Globally, we recognize that research has a role to play in our recovery from a pandemic, in learning to live alongside COVID-19, and in reimagining our futures on a local, regional, national and global level. In this context, the practices of engagement become very important, recognizing the expertise of people working in all sectors and none, in coming together to change how the world works.

As we slowly emerge from the pandemic, we will need to learn and relearn the art of collaboration, the role of research and knowledge, and the value of different perspectives and approaches. The journal provides a space to develop a knowledge base that can contribute to changing how people think, changing what people do and changing how the world works.

\section{Articles in this issue}

Bridges, E. (2021) 'Small grants, big impact: The Institute of Classical Studies' seed funding scheme for public engagement'. Research for All, 5 (2), 290-301. https://doi.org/10.14324/RFA.05.2.07.

Clarke, P. (2021) 'Future Places Toolkit: Engaging communities through augmented reality and performance'. Research for All, 5 (2), 205-26. https://doi.org/10.14324/RFA.05.2.03.

Cole, E. (2021) 'Knowledge exchange and the creative industries: A reflective commentary on current practice'. Research for All, 5 (2), 194-204. https://doi.org/10.14324/RFA.05.2.02.

Dawson, L., Hay, J. and Rosling, N. (2021) 'Therapeutic creativity and the lived experience of grief in the collaborative fiction film Lost Property'. Research for All, 5 (2), 227-45.

https://doi.org/10.14324/RFA.05.2.04. 
Dreyer, M., Kosow, H., Bauer, A., Chonkova, B., Kozarev, V. and Timotijevic, L. (2021) 'Public engagement with research: Citizens' views on motivations, barriers and support'. Research for All, 5 (2), 302-19. https://doi.org/10.14324/RFA.05.2.08.

Gray, S., Bevan, C., Cater, K., Gildersleve, J., Garland, C. and Langdon, O. (2021) 'Developing arts-based methods for exploring virtual reality technologies: A university-industry case study'. Research for All, 5 (2), 246-70. https://doi.org/10.14324/RFA.05.2.05.

Keith, L. and Griffiths, W. (2021) 'SCENE: A novel model for engaging underserved and underrepresented audiences in informal science learning activities'. Research for All, 5 (2), 320-46. https://doi.org/10.14324/RFA.05.2.09

Mathieson, A. and Duca, E. (2021) 'STEM escape rooms for public engagement'. Research for All, 5 (2), 347-55. https://doi.org/10.14324/RFA.05.2.10.

Moreton, S. (2021) 'Knowledge exchange in the arts and humanities as creative economy policy assemblage'. Research for All, 5 (2), 271-89. https://doi.org/10.14324/RFA.05.2.06.

Morris, S. and Stevenson, O. (2021) 'The dynamics of working at intersections: Reflections from exploring inequalities'. Research for All, 5 (2), 356-65. https://doi.org/10.14324/RFA.05.2.11.

Ní Shúilleabháin, A., McAuliffe, F. and Ní Shé, É. (2021) '"Bottoms up": A case study on integrating public engagement within a university culture'. Research for All, 5 (2), 366-81. https://doi. org/10.14324/RFA.05.2.12.

Pick, D., Hallsworth, M.-C. and Marks, S. (2021) 'Hidden persuaders on film: Exploring young people's lived experience through visual essays'. Research for All, 5 (2), 382-98. https://doi. org/10.14324/RFA.05.2.13.

Sadler, W.J. (2021) 'Evaluating the short-term and long-term impact of an interactive science show'. Research for All, 5 (2), 399-19. https://doi.org/10.14324/RFA.05.2.14.

Salter, S., Altdörfer, T., Brown, G. and Carpenter, M. (2021) 'Meeting the challenges of public engagement, research impact and research participation as a baby and child lab'. Research for All, 5 (2), 420-37. https://doi.org/10.14324/RFA.05.2.15.

Sheppard, Z.A., Williams, S., Lawson, R. and Appleby, K. (2021) 'Patient and public involvement and engagement: Practice case study with reflections and learnings from a small rural district general hospital'. Research for All, 5 (2), 438-47. https://doi.org/10.14324/RFA.05.2.16.

Stelfox, M., Martin-Cereceda, M., Vahed, K., Hudgins, J., Köhnk, S., lqbal, U., Shameel, I., Hancock, J.M. and Sweet, M. (2021) 'The Olive Ridley Project (ORP): A successful example of how to engage researchers, conservation practitioners and civil society'. Research for All, 5 (2), 448-73. https://doi.org/10.14324/RFA.05.2.17.

\section{Acknowledgements}

We would like to thank Emma Cole for organizing the submission of papers contained in the Knowledge Exchange and the Creative Industries special feature.

Research for All is a collaborative project that relies on a range of associate editors with experience of engaged research in a variety of contexts. The associate editors who advised us on the content for this issue of the journal are:

- Helen Featherstone - University of Bath, UK

- Sam Gray - Manchester Metropolitan University, UK

- Joanna Heaton-Marriott - University of Lancaster, UK

- Hilary Jackson - Public Engagement Consultant, UK

- Paul Manners - National Co-ordinating Centre for Public Engagement, UK

- Gene Rowe - Gene Rowe Associates, UK

- Suzanne Spicer - University of Manchester, UK

- Norbert Steinhaus - Living Knowledge: The International Science Shop Network, Germany

- Ruth Stewart - University of Johannesburg, South Africa

- Gillian Stokes - UCL Institute of Education, UK

We extend our thanks to them and to all the expert reviewers - two for each contribution who helped us guide authors towards their final drafts. 


\section{References}

Duncan, S. and Oliver, S. (2017a) 'Editorial'. Research for All, 1 (1), 1-5. https://doi.org/10.18546/ RFA.01.1.01.

Duncan, S. and Oliver, S. (2017b) 'Editorial: Motivations for engagement'. Research for All, 1 (2), 229-33. https://doi.org/10.18546/RFA.01.2.01.

Duncan, S. and Oliver, S. (2018) 'Editorial: Creating the conditions for engagement to thrive'. Research for All, 2 (2), 179-84. https://doi.org/10.18546/RFA.02.2.01.

Duncan, S. and Oliver, S. (2019) 'Editorial: The humanity of engagement at the core of developing and sharing knowledge'. Research for All, 3 (2), 125-8. https://doi.org/10.18546/RFA.03.2.01.

Duncan, S. and Oliver, S. (2020) 'Editorial: Engagement in a time of great change'. Research for All, 4 (2), 145-9. https://doi.org/10.14324/RFA.04.2.01.

NCCPE (National Co-ordinating Centre for Public Engagement) (n.d.) 'What is public engagement?'. Accessed 21 June 2021. www.publicengagement.ac.uk/about-engagement/ what-public-engagement.

NCCPE (National Co-ordinating Centre for Public Engagement) (2016) Engaging Publics with Research: Reviewing the REF impact case studies and templates. Accessed 21 June 2021. www.publicengagement.ac.uk/sites/default/files/publication/nccpe_ref_review_executive_ summary.pdf.

NCCPE (National Co-ordinating Centre for Public Engagement) (2018) Developing Further Guidance on Impact Arising from Public Engagement in REF 2021. Accessed 21 June 2021. www. ref.ac.uk/media/1037/ref-2021-impact-workshop-impact-arising-from-public-engagement.pdf.

Oliver, S. and Duncan, S. (2019) 'Editorial: Looking through the Johari window'. Research for All, 3 (1), 1-6. https://doi.org/10.18546/RFA.03.1.01.

Oliver, S. and Duncan, S. (2020) 'Editorial: Time for sharing knowledge'. Research for All, 4 (1), 1-5. https://doi.org/10.18546/RFA.04.1.01.

Oliver, S. and Duncan, S. (2021) 'Editorial: Achieving and demonstrating innovation and new learning in public engagement'. Research for All, 5 (1), 1-4. https://doi.org/10.14324/RFA.05.1.01. 